\title{
Antioxidant Effects of Schisandra chinensis Fruits and Their Active Constituents
}

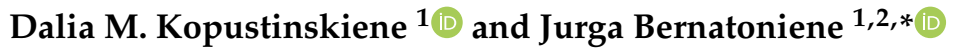 \\ 1 Institute of Pharmaceutical Technologies, Faculty of Pharmacy, Medical Academy, Lithuanian University of \\ Health Sciences, Sukileliu pr. 13, LT-50161 Kaunas, Lithuania; DaliaMarija.Kopustinskiene@lsmuni.lt \\ 2 Department of Drug Technology and Social Pharmacy, Faculty of Pharmacy, Medical Academy, Lithuanian \\ University of Health Sciences, Sukileliu pr. 13, LT-50161 Kaunas, Lithuania \\ * Correspondence: Jurga.Bernatoniene@lsmuni.lt
}

check for

updates

Citation: Kopustinskiene, D.M.; Bernatoniene, J. Antioxidant Effects of Schisandra chinensis Fruits and Their Active Constituents. Antioxidants 2021, 10, 620. https:// doi.org/10.3390/antiox10040620

Academic Editor: Stefania D’Angelo

Received: 25 March 2021

Accepted: 16 April 2021

Published: 18 April 2021

Publisher's Note: MDPI stays neutral with regard to jurisdictional claims in published maps and institutional affiliations.

Copyright: (c) 2021 by the authors. Licensee MDPI, Basel, Switzerland. This article is an open access article distributed under the terms and conditions of the Creative Commons Attribution (CC BY) license (https:// creativecommons.org/licenses/by/ $4.0 /)$.

\begin{abstract}
Schisandra chinensis Turcz. (Baill.) fruits, their extracts, and bioactive compounds are used in alternative medicine as adaptogens and ergogens protecting against numerous neurological, cardiovascular, gastrointestinal, liver, and skin disorders. S. chinensis fruit extracts and their active compounds are potent antioxidants and mitoprotectors exerting anti-inflammatory, antiviral, anticancer, and anti-aging effects. S. chinensis polyphenolic compounds-flavonoids, phenolic acids and the major constituents dibenzocyclooctadiene lignans are responsible for the S. chinensis antioxidant activities. This review will focus on the direct and indirect antioxidant effects of $S$. chinensis fruit extract and its bioactive compounds in the cells during normal and pathological conditions.
\end{abstract}

Keywords: Schisandra chinensis; lignan; schisandrin B; antioxidant; pro-oxidant; mitochondria

\section{Introduction}

Schisandra chinensis Turcz. (Baill.) belongs to the Schisandraceae family. The plants are native to northeastern China, Japan, Korea, Manchuria, and the Far East part of Russia. Their purple-red berries are called five-flavor fruits because of the sweet, bitter, pungent, salty, and sour taste [1-5]. S. chinensis is widely used as an herbal supplement in traditional Chinese medicine and in Western phytotherapy [1,2,4,5], whereas in Russia-as a potent adaptogen, improving disease and stress tolerance, and increasing energy, endurance, and physical performance $[2,3]$.

$S$. chinensis is used as a preservative and an additive in food technology to enhance the flavor, taste, and nutritional value to the food [2]. The dried fruits of the S. chinensis and their extracts are helpful in the treatment of neurological, cardiovascular, and gastrointestinal disorders, in decreasing fatigue, reducing obesity, and protecting from mitochondrial dysfunction, insomnia, and the excessive sweating [1,2,5]. They stimulate immunity, act as a tonic, and exert antioxidant, anti-inflammatory, antiviral, anticancer, anti-aging, antidiabetic, and liver- and skin-protecting activities [1-5].

\section{Chemical Properties of Schisandra chinensis Fruit Constituents}

S. chinensis fruits contain about $1.5 \%$ sugars (polysaccharides and monosaccharides; glucose, fructose, galactose, and arabinose), tannins (hydrolysable, e.g., gallic acid esters, and condensed, e.g., proanthocyanidins and catechol-type tannins), color substances (mainly anthocyanins), and about 3\% essential oils, with sesquiterpenes as the dominant compounds [6]. $\alpha$-Bergamotene, $\beta$-chamigrene, $\beta$-himachalene, and ylangene are the main components of essential oils (about $75 \%$ ), whereas oxygenated sesquiterpenes, monoterpenes, and oxygenated monoterpenes comprise the smaller part (about 5\%) [6]. Chemical investigations also revealed the presence of triterpenoids (lanostane and cycloartane-type triterpenoids and nortiterpenoids), organic acids (citric, fumaric, malic, and tartaric acids), 
phenolic acids (chlorogenic, gentisic, p-hydroxybenzoic, p-coumaric, protocatechuic, syringic, and salicylic acids) $[7,8]$, flavonoids (quercetin, isoquercitrin, rutin, and hyperoside) [8], vitamins $\mathrm{C}$ and $\mathrm{E}$, phytosterols, and bioelements $(\mathrm{Cr}, \mathrm{Cu}, \mathrm{Co}, \mathrm{Ca}, \mathrm{Mg}, \mathrm{Fe}, \mathrm{Zn}, \mathrm{Mn}$, $\mathrm{B}, \mathrm{Ni}),[1,7,9]$.

The major active compounds of $S$. chinensis (Figure 1) are dibenzocyclooctadiene lignans [1]. Schisandrin is the most dominant $S$. chinensis lignan found in the amounts of $2.2-5.3 \mathrm{mg} / \mathrm{g}$ in S. chinensis fruit $[2,10]$.

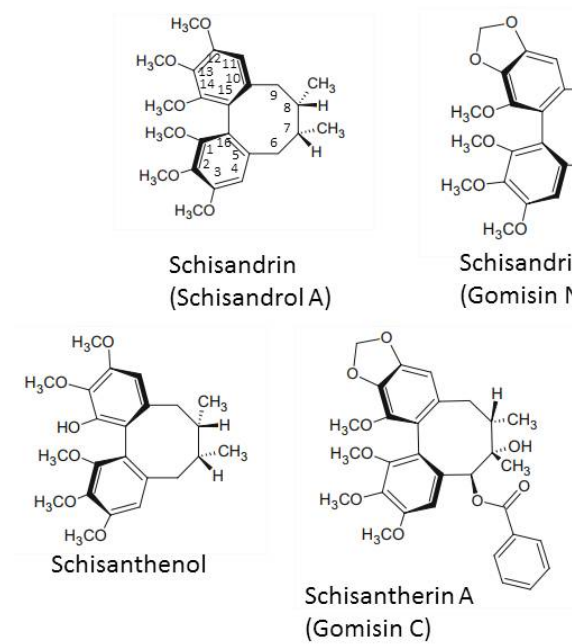

Schisandrin (Schisandrol A)

(Gomisin C)

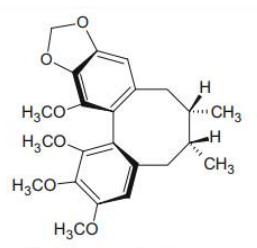

Schisandrin B
(Gomisin N)

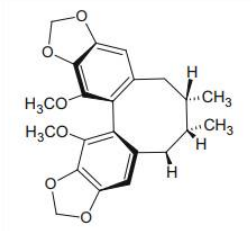

Schisandrin C

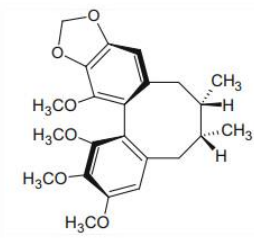

$\gamma$-Schisandrin

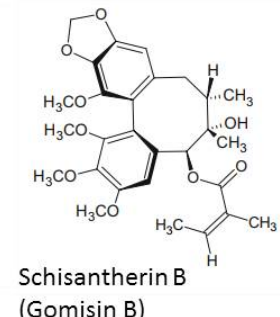

(Gomisin B)

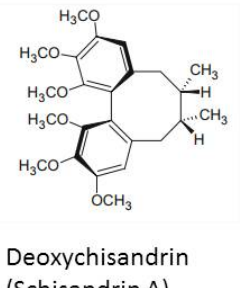

(Schisandrin A)

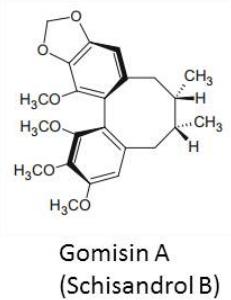

Figure 1. Chemical structures of main Schisandra chinensis lignans.

Anticancer activity of $S$. chinensis lignans is decreased in the presence of a hydroxyl group at the C7 position, thus resulting in increased hydrophilicity and decreased permeability into the lipid bilayer [11], whereas a methylenedioxy group between $\mathrm{C} 12$ and C13 enhanced anticancer activity. A 1,2,3-trimethoxy moiety, a 6-acyloxy group, and the absence of a 7-hydroxy group resulted in P-glycoprotein inhibition and also increased $S$. chinensis anticancer efficacy [12]. Gomisin N and deoxyschisandrin were the most effective anticancer lignans of $S$. chinensis $[11,12]$. S. chinensis lignans without an ester group at C6, a hydroxyl group at C7, or a methylene dioxy moiety, and with an R-biphenyl configuration possess strong antiplatelet activity, with 6,7-dehydroschisandrol A as the most active compound [13]. The exocyclic methylene group in S. chinensis lignan structure is necessary for the antioxidant activity, which is enhanced even more in the presence of the benzoyloxy group [14].

\section{Bioavailability of Schisandra chinensis Fruit Extract and Its Constituents}

The bioavailability studies of $S$. chinensis products were mainly performed in animals. A maximum concentration of schisandrin of $0.08 \pm 0.07$ and $0.15 \pm 0.09 \mu \mathrm{g} / \mathrm{mL}$ was achieved after oral administration of $3 \mathrm{~g} / \mathrm{kg}$ and $10 \mathrm{~g} / \mathrm{kg}$ of $S$. chinensis fruit extract in rats [15]. In a parallel study, schisandrin $(10 \mathrm{mg} / \mathrm{kg}$, administered intravenously (i.v.) or orally (p.o.)) and the herbal extract of S. chinensis ( $\mathrm{g} / \mathrm{kg}$ and $10 \mathrm{~g} / \mathrm{kg}$, p.o.) were given indivi-dually to rats [15]. The dose of $S$. chinensis $(3 \mathrm{~g} / \mathrm{kg})$ was equivalent to schisandrin $(5.2 \mathrm{mg} / \mathrm{kg})$, whereas the dose of $S$. chinensis $(10 \mathrm{~g} / \mathrm{kg})$ was equivalent to schisandrin $(17.3 \mathrm{mg} / \mathrm{kg})$ [15]. Thus, in rats, the oral bioavailability of schisandrin was approximately $15.56 \pm 10.47 \%$ [15]. When Sprague-Dawley rats were administered $2 \mathrm{mg} / \mathrm{kg}$ (i.v.) or $10 \mathrm{mg} / \mathrm{kg}$ (intragastrically (i.g.)) of schisandrol B, or $6 \mathrm{~mL} / \mathrm{kg}$ (i.g.) of S. chinensis extract (equivalent to $15 \mathrm{mg} / \mathrm{kg}$ schisandrol B), the oral absolute bioavailability of schisandrol B was approximately $18.73 \%$ and $68.12 \%$, respectively [16]. Schisandrin B could modulate cytochrome P450 3A activity (CYP3A) in vivo in rats and also altered the pharmacokinetic profiles of other CYP3A substrates [17]. The tissue distribution studies showed that schisandrin B [18] and schisandrol B were distributed throughout several tested tissues 
and accumulated mainly in in the liver and kidneys [16,18]. Absolute oral bioavailability of schisandrin B depended on the sex of animals-it was approximately $55.0 \%$ for female rats and $19.3 \%$ for male rats [19]. The linear pharmacokinetics properties were observed within the range of the tested oral dose $(10,20$, and $40 \mathrm{mg} / \mathrm{kg}$ rat $)$ of schisandrin B [19]. Schisandrin B was extensively distributed in ovary and adipose tissue [19]. The urinary, biliary, and fecal excretion of schisandrin B was very low; schisandrin B was excreted mainly in the form of metabolites [20].

In alternative medicine, $S$. chinensis dried fruit powder is usually administered to patients at a dose of 0.5-1.5 g twice per day before meals over a period of 20-30 days [3]. No serious adverse effects were reported during use of $S$. chinensis; however, overdose may cause dyspnea, restlessness, or insomnia $[2,3,5]$.

\section{Biological Activity of Schisandra chinensis Fruit Extract and Its Constituents: Main Mechanisms of Action}

Dried S. chinensis fruits, their extracts, and their bioactive constituents exert a wide variety of beneficial effects under normal and pathological conditions (Figure 2). S. chinensis bioactive compounds are antioxidants, detoxifiers, powerful hepatoprotectors, hypoglycemic agents, inflammation suppressors, neuro- and cardioprotectors, immunostimulants, and tumor suppressors [1-3,5]. They demonstrate antibacterial and antiviral properties, and suppress platelet aggregation; they also are potent adaptogens and ergogens, capable to decrease fatigue and support the normal functioning of cellular powerhousesmitochondria [2,7]. S. chinensis bioactive compounds are also potent skin-protectors. Their anti-aging and revitalizing actions comprise moisturizing, toning, irritation-soothing, and wound-healing, reducing dilatation of blood vessels and restoring the skin protective barrier.

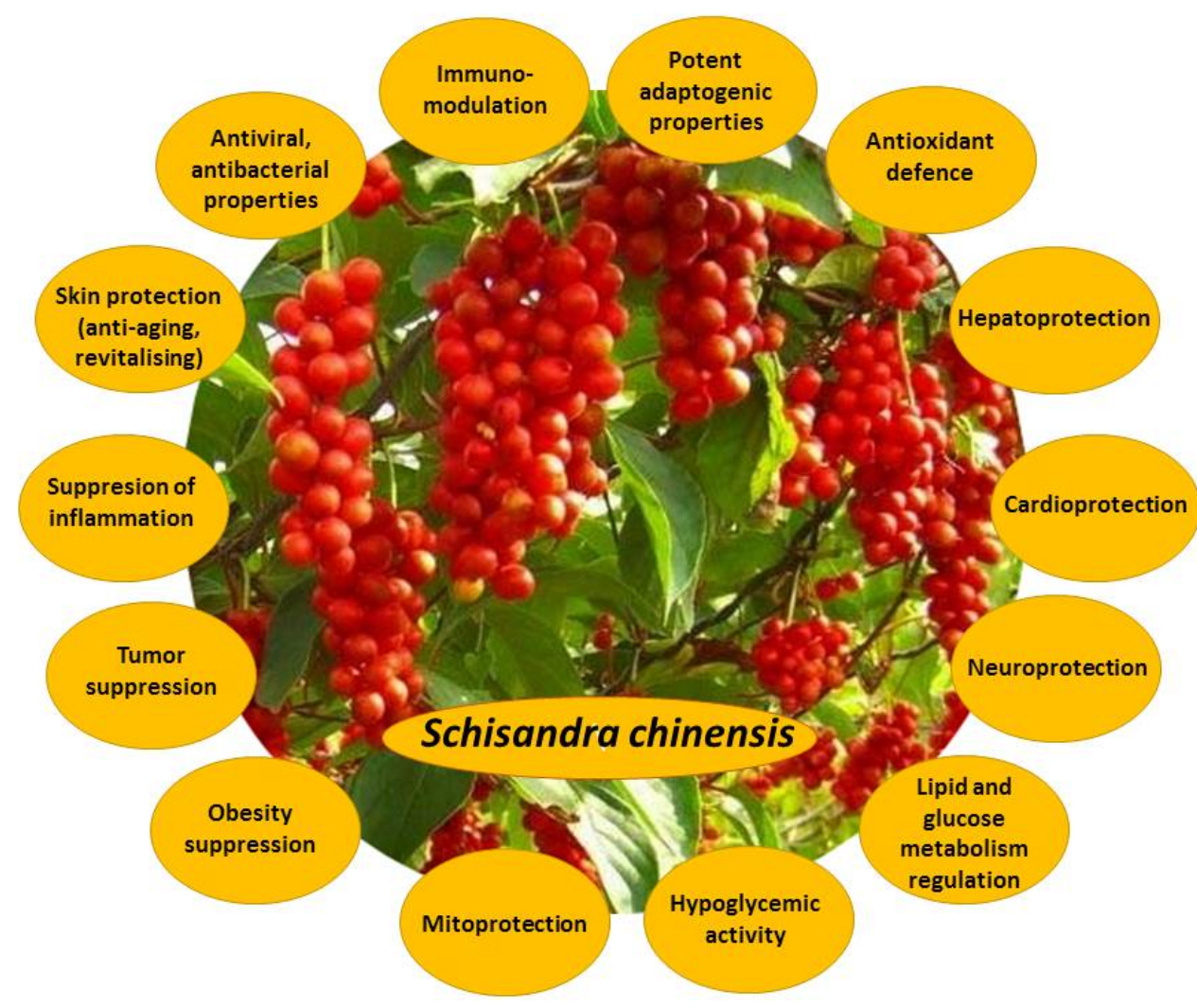

Figure 2. Main biological effects of Schisandra chinensis fruit extracts and their bioactive compounds.

Principal mechanisms of beneficial actions of $S$. chinensis bioactive compounds include activation of the antioxidant defense system, reducing the levels of aspartate aminotransferase, alanine aminotransferase, and serum and liver glutamic pyruvic transaminase, as 
well as inactivation of cytochrome P450 [21]. S. chinensis bioactive compounds inhibit pro-oxidant signaling pathways: cyclooxygenase 1 and 2 (COX-1 and 2) [22], nitric oxide production [23], and gene expression of pro-inflammatory cytokines [24]. Furthermore, S. chinensis constituents block calcium channels $\left(\mathrm{Ca}^{2+}\right)$ [25] and inhibit the opening of the mitochondrial permeability transition pore (mPTP), thus protecting from cell death [25-27]. In tumor cells, $S$. chinensis bioactive compounds can reverse multidrug resistance dependent on P-glycoprotein (Pgp-MDR) [28] and sensitize tumor cells to antitumor treatments, e.g., with doxorubicin $[29,30]$. They can also promote cell cycle arrest, thus suppressing proliferation and activating apoptosis and autophagy [31-33].

\section{Antioxidant Activity of Schisandra chinensis Fruit Extract and Its Constituents}

Impaired balance in pro-oxidant and antioxidant homeostasis causes oxidative stress, which enhances the production of toxic reactive oxygen species (ROS). ROS in the cells are mainly generated in mitochondria as by-products of the mitochondrial respiratory chain, whereas some of them can be derived also from redox metal ion-related and enzymatic sources $[34,35]$. ROS are neutralized by enzymatic and non-enzymatic endogenous antioxidant defense systems. Superoxide dismutase (SOD), catalase (CAT), glutathione peroxidase (GPx), and glutathione reductase (GR) belong to the enzymatic defense system, while small antioxidant molecules, such as vitamin $C$, vitamin $E$, and reduced glutathione (GSH), make part of non-enzymatic defense [34].

As with many plant-derived antioxidants, $S$. chinensis active compounds can directly scavenge reactive oxygen species, activate the antioxidant defense system under normal conditions, and act as pro-oxidants under pathological conditions (Figure 3).

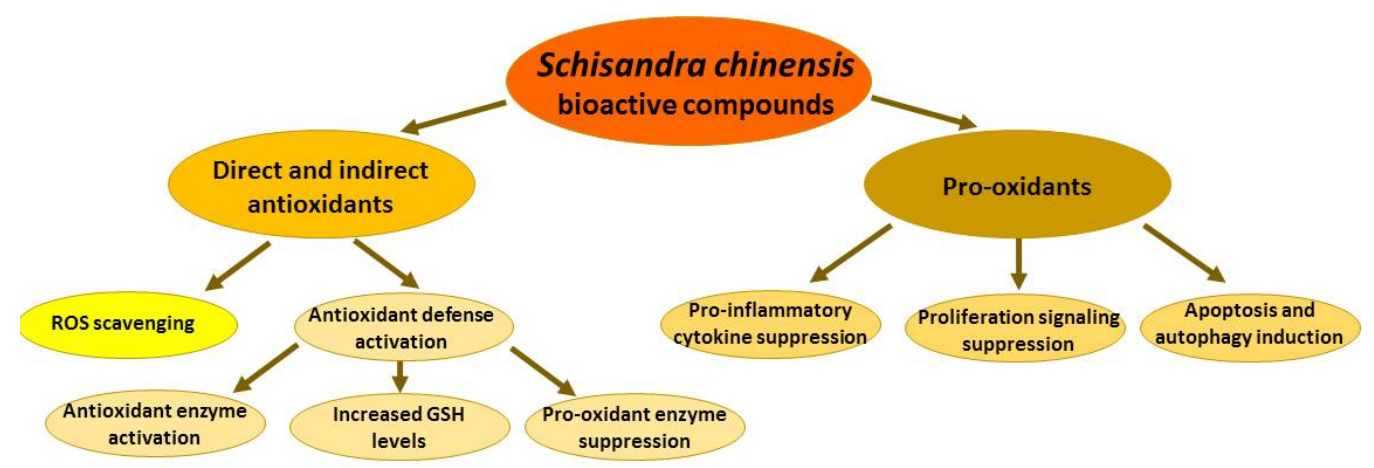

Figure 3. Antioxidant and pro-oxidant activities of Schisandra chinensis fruit extracts and their bioactive compounds. ROS-reactive oxygen species.

Regarding S. chinensis polyphenolic compounds: Flavonoids, phenolic acids, and the major constituents of dibenzocyclooctadiene lignans are considered to be responsible for the antioxidant activities of $S$. chinensis fruit extract $[2,4]$.

\subsection{Direct ROS Scavenging by Schisandra chinensis Fruit Extract and Its Constituents}

The direct ROS scavenging capability of $S$. chinensis ethanolic extracts was demonstrated by Mocan A et al. using the DPPH bleaching assay, Trolox equivalent antioxidant capacity assay, hemoglobin ascorbate peroxidase activity inhibition, and the inhibition of lipid peroxidation catalyzed by cytochrome $c$ assays and an electron paramagnetic resonance spectroscopy [8]. S. chinensis fruit ethanolic extract could directly scavenge ROS, thus alleviating hydrogen peroxide $\left(\mathrm{H}_{2} \mathrm{O}_{2}\right)$-induced inhibition of $\mathrm{C} 2 \mathrm{C} 12$ cell growth [36]. Moreover, different schisandrins could neutralize ROS from human polymorphonuclear leukocytes stimulated with phorbol myristate acetate [37].

The relative order of the strength of ROS scavenging of schisandrins depended on their conformation and the presence of the dioxymethyl group capable of attracting electrons, thus facilitating radical attack: $\mathrm{S}(-)$-schisandrin $\mathrm{B}>\mathrm{S}(+)$-schisandrin $>$ schisandrin $\mathrm{C}>$ 
schisandrin B [37]. The ROS scavenging effect of schisandrin B was similar to that of vitamin C [38]. Fenton reaction, xanthine-xanthine oxidase, or UV-irradiation of riboflavin assays revealed that the $S$. chinensis lignan schisanhenol could neutralize ROS better than vitamin $\mathrm{E}$ in an experimental model of tetradecanoylphorbol acetate-stimulated human neutrophils [39]. Furthermore, in in vitro studies, S. chinensis fruit aqueous extract protected human blood lymphocyte DNA from oxidant challenge by $\mathrm{H}_{2} \mathrm{O}_{2}$, evaluated by comet assay [40].

\subsection{Effects of Schisandra chinensis Fruit Extract and Its Constituents on Enzymatic and Non-Enzymatic Endogenous Antioxidant Defense Systems}

S. chinensis bioactive compounds exerted antioxidant activities in many tissues including the brain [41]. In a D-galactose-induced Wistar rat neurotoxicity model, S. chinensis aqueous or ethanolic extracts decreased SOD, CAT, and total antioxidants, and maintained the normal levels of GSH, malondialdehyde (MDA), and nitric oxide (NO) in the serum, striatum, hippocampus, and prefrontal cortex, thus ameliorating cognitive deficits assessed using the Morris water maze and the step-down type passive avoidance test [42]. Schisandrin B $(10,25$, or $50 \mathrm{mg} / \mathrm{kg}$ administered orally (p.o.) for 7 days) could increase the levels of antioxidant enzymes, such as SOD, GPx, and cellular GSH in mice, and suppress lipid peroxidation in scopolamine- and cisplatin-induced cerebral oxidative stress [43]. Furthermore, schisandrin B exerted neuroprotective activity by reducing MDA levels and ROS generation, while in the meantime enhancing SOD activity and GSH production in the mice force swimming stress model, thus reducing anxiety-like behavior [44]. Schisandrin B $(5,10$, or $20 \mu \mathrm{M})$ could suppress the production of ROS in microglia-neuron co-cultures [45]. Antioxidant effects of the $S$. chinensis lignan deoxyschisandrin $(4,12$, and $36 \mathrm{mg} / \mathrm{kg}$ i.g. for 14 days) were investigated on the amyloid-beta (1-42) A $\beta(1-42)$-induced memory impairment model in mice [46]. Deoxyschisandrin improved A $\beta(1-42)$-induced short-term and spatial memory impairments assessed using the Y-maze and water maze tests. In the cerebral cortex and hippocampus of mice, deoxyschisandrin restored the suppression of SOD and GPx activities, increased GSH levels and the GSH/oxidized glutathione (GSSG) ratio, and decreased MDA and GSSG levels [46], thus alleviating cognitive decline in Alzheimer's disease [46]. The effects of S. chinensis lignan schisandrin C $(15 \mu \mathrm{g} / \mathrm{kg}$ or $150 \mu \mathrm{g} / \mathrm{kg} /$ day for five days in the lateral cerebral ventricles using sterotaxically implanted cannula) on pathological changes and memory impairment were evaluated in the $\mathrm{A} \beta(1-$ 42)-induced Alzheimer's disease model in mice [47]. Schisandrin C restored cognitive functions and decreased neuronal injury by inhibiting total cholinesterase, enhancing SOD and GPx activities and increasing GSH levels in the hippocampus and cerebral cortex [47]. In the scopolamine-treated mice model, schisanthenol (10, 30, $100 \mathrm{mg} / \mathrm{kg} /$ day i.p. for seven days) improved learning and memory ability assessed by the Morris water maze test [48]. In mice, hippocampus schisanthenol enhanced the activity of SOD and GPx, while it decreased the content of MDA and acetylcholinesterase [48].

$S$. chinensis bioactive compounds were hepatoprotective in various liver intoxication models [1,2]. In in vitro studies, S. chinensis lignans schisanthenol, schisandrin B, and schisandrin $\mathrm{C}$ at a concentration of $1 \mathrm{mM}$ suppressed iron/cysteine induced lipid peroxidation, assessed by a decrease in MDA formation in rat liver microsomes, and did so more effectively than vitamin E [49]. In AML12 hepatocytes, schisandrin B (15 $\mu \mathrm{M})$ could induce glutathione antioxidant response [50]. S. chinensis fruit extract and its active compound-schisandrin B-protected against carbon tetrachloride-induced hepatotoxicity by increasing mitochondrial GSH levels and enhancing activities of GR, GPx, and glutathione S-transferases in carbon tetrachloride-intoxicated mice [51-53]. Schisandrin B (3 mmol $/ \mathrm{kg} /$ day p.o. for three days) was also protective in the carbon tetrachlorideinduced mice hepatotoxicity model by increasing the hepatic vitamin $\mathrm{C}$ and vitamin $\mathrm{E}$ levels, as well as mitochondrial GSH levels [54]. Lignan-enriched S. chinensis fruit extract ameliorated the hepatic antioxidant/detoxification system in rats after aflatoxin beta 1 or cadmium chloride challenge by increasing hepatic GSH levels and hepatic GR, and glutathione S-transferase activities [55]. In addition, 5-hydroxymethyl-2-furfural isolated 
from S. chinensis fruit $(7.5,15$, and $30 \mathrm{mg} / \mathrm{kg}$ p.o. for seven days) was hepatoprotective in the acute alcohol-induced liver oxidative injury model in mice by decreasing the levels of MDA and increasing CAT, GPx, and SOD activities in liver tissue [56].

S. chinensis fruit extract and its active constituent schisandrin B exerted cardioprotective effects by enhancing the heart antioxidant defense system [57-61]. S. chinensis fruit extract protected from adriamycin-induced cardiotoxicity in rats by decreasing MDA levels and increasing activities of myocardial GPx and SOD [60]. Lignan-enriched S. chinensis extract protected heart from oxidative damage in an in vivo model of myocardial infarction and an ex vivo model of myocardial ischemia-reperfusion injury in rats [61]. Moreover, schisandrin B and C (10-30 $\mu \mathrm{M})$, but not schisandrin A, stimulated the cytochrome $\mathrm{P}-450$-catalysed NADPH oxidation reaction in in vitro studies of rat heart microsomes and/or ROS production in rat hearts (a single dose of $1.2 \mathrm{mmol} / \mathrm{kg}$ ), resulting in the increase in mitochondrial GSH levels during, thus protecting against ischemia/reperfusion injury [59]. During doxorubicin-induced cardiomyopathy in mice, schisandrin B (25$100 \mathrm{mg} / \mathrm{kg} /$ day per os for five days) reduced lipid peroxidation, prevented nitrotyrosine formation, and suppressed metalloproteinase activation in the heart [58]. During myocardial ischemia/reperfusion ( $40 \mathrm{~min}+1 \mathrm{~h})$ in rats, schisandrin B $(20 \mathrm{mg} / \mathrm{kg})$ decreased MDA levels and increased total SOD activity, thus attenuating oxidative injury [57].

Schisandrin B in HK-2 cells $(2.5-10 \mu \mathrm{M})$ and in mice $(20 \mathrm{mg} / \mathrm{kg} /$ day per os for four weeks) decreased renal MDA levels and enhanced GSH production in cyclosporine Ainduced nephrotoxicity [62]. Furthermore, in gentamicin-induced nephrotoxicity in rats, schisandrin B (1-10 mg/kg/day for 15 days) exerted nephroprotective effects by enhancing renal mitochondrial antioxidant status: increasing GSH and alpha-tocopherol levels and activating SOD [26].

S. chinensis ethanol extract and ethanol-water extract significantly decreased the pulmonary MDA levels and increased SOD activity and GSH levels in a guinea pig model of cough hypersensitivity induced by 14 days of cigarette smoke exposure [63].

\subsection{Effects of Schisandra chinensis Fruit Extract and Its Constituents on the Pro-Oxidant Enzymes}

Besides the mitochondrial electron transport chain, the potential ROS sources in the cells are enzymatic reactions catalyzed by the pro-oxidant enzymes: NADPH oxidases and the arachidonic acid-metabolizing enzymes-cyclooxygenases and lipoxygenases, xanthine oxidase, nitric oxide (NO) synthases, and the cytochrome P450 [35]. S. chinensis fruit extract and its bioactive compounds could effectively protect against inflammation due to the suppression of pro-oxidant enzyme activities [2,5].

S. chinensis fruit water extract inhibited gene expression of inducible NO synthase (iNOS) and cyclooxygenase-2 (COX-2) in lipopolysaccharide (LPS)-stimulated RAW 264.7 macrophage cells, thus suppressing the protein kinase B (Akt)-dependent nuclear factorkappa B (NF-kB) signaling pathway without any cytotoxic effect [64]. The S. chinensis lignan schisandrin $(5-100 \mu \mathrm{M})$ demonstrated anti-inflammatory activities in vitro by inhibiting NO production, iNOS, and COX-2 expression in the LPS-treated RAW 264.7 macrophage cell line, thus suppressing NF- $\mathrm{KB}$, c-Jun N-terminal kinase (JNK), and the p38 mitogen-activated protein kinase (MAPK) signaling pathways [65]. Schisantherin A $(0.5-25 \mathrm{mg} / \mathrm{L})$, in a concentration-dependent manner, could block NF- $\mathrm{KB}$ and MAPK signaling in lipopolysaccharide (LPS)-stimulated RAW 264.7 macrophages by decreasing NO production, iNOS, and COX-2 activities [66]. Schisandrin A $(9-47 \mu \mathrm{M})$ exerted antiinflammatory effects in interleukin- $1 \beta$-stimulated human osteoarthritis chondrocytes by reducing NO production, suppressing iNOS and COX-2 activities, thus blocking NF- $\mathrm{kB}$ and MAPK signaling [67]. Schisandrin B $(5,10$ or $20 \mu \mathrm{M})$ protected against microglial-mediated inflammatory injury in microglia-neuron co-cultures by downregulating NADPH oxidase and other pro-inflammatory enzymes [45]. 


\section{Effects of Schisandra chinensis Fruit Extract and Its Constituents on Mitochondria}

Mitochondria play a crucial role in calcium homeostasis, apoptosis, and metabolism regulation under normal and pathological conditions in the cells [68]. Mitochondria are responsible for cellular energy supply via oxidative phosphorylation, generating ROS as a by-product during this process [69]. The excessive ROS trigger numerous events in signal transduction pathways modulating inflammation, apoptosis, proliferation, and immune response $[68,69]$. S. chinensis fruits, their extracts, and their bioactive constituents help to restore impaired mitochondrial functions, acting as mitoprotective agents (Figure 4).

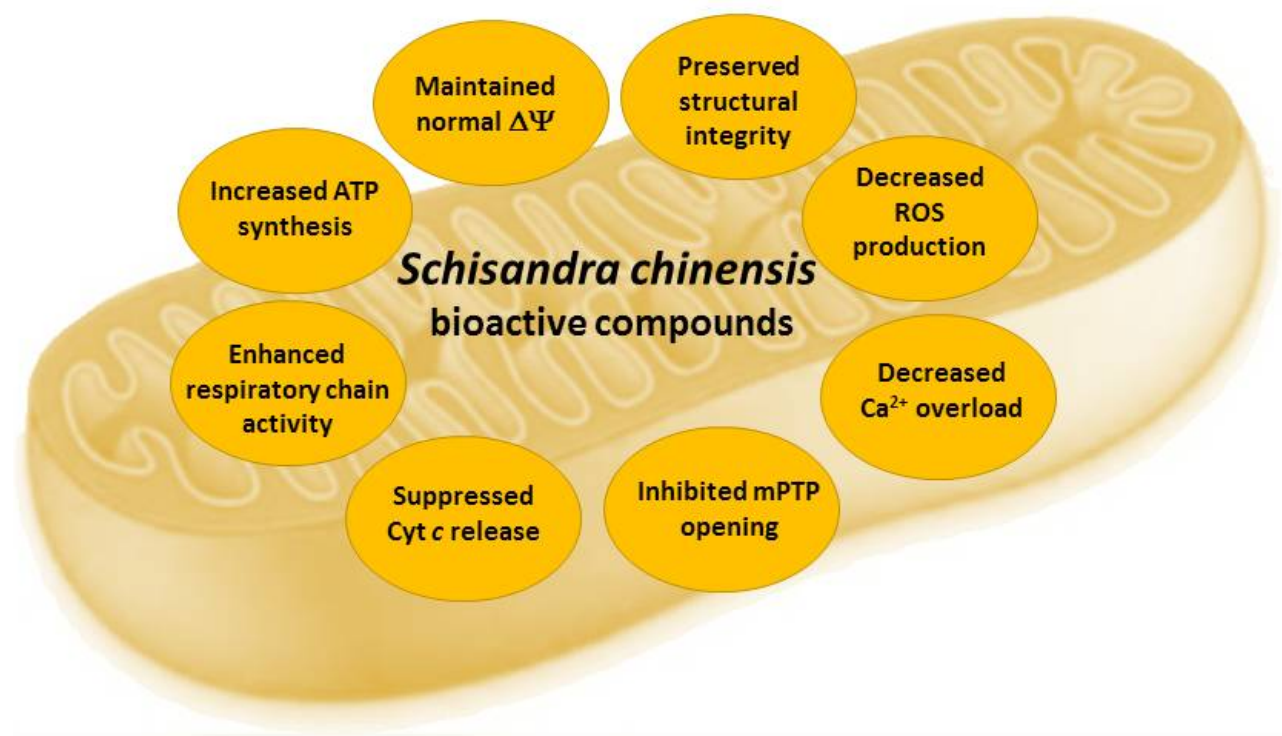

Figure 4. Effects of Schisandra chinensis fruit extracts and their bioactive compounds in mitochondria. $\Delta \Psi$-mitochondrial membrane potential, $\mathrm{mPTP}$ - mitochondrial permeability transition pore, ROSreactive oxygen species.

In the $\mathrm{A} \beta(1-42)$ oligomer-treated rat primary hippocampal neuron model, schisandrin $(2 \mu \mathrm{g} / \mathrm{mL})$ alleviated impaired mitochondrial functions, energy metabolism, mitochondrial biogenesis, and dynamics [70]. Schisandrin restored mitochondrial membrane potential cytochrome c oxidase activity, protected the opening of mitochondrial permeability transition pore, and decreased the release of cytochrome c [70]. Furthermore, schisandrin improved ATP production, citrate synthase activity, and the process of mitochondrial fusion and fission [70]. The S.chisandra lignan gomisin J up-regulated apoptosis signaling and decreased the dissociation of hexokinase II from the voltage-dependent anion channel (VDAC) in mitochondria, thus reducing aerobic glycolysis in glioma cell lines [71]. Mixture of $S$. chinensis extract and ascorbic acid restored mitochondrial respiration, improved cognitive function, and induced synaptic plasticity in mice [72].

Schisandrin B protected from ROS generation, lipid peroxidation, protein oxidation, and DNA damage in tert-butyl hydroperoxide-injured human keratinocyte-derived $\mathrm{HaCaT}$ cells by reducing the loss of the mitochondrial membrane potential, restoring adenosine triphosphate levels, and enhancing the expression of key antioxidant enzymes-catalase, superoxide dismutase, glutathione peroxidase, and heme oxygenase-1 [73]. The $S$. chinensis lignan schisandrin A protected against $\mathrm{H}_{2} \mathrm{O}_{2}$-induced cytotoxicity and DNA damage in $\mathrm{C} 2 \mathrm{C} 12$ cells by restoring ATP levels, maintaining the mitochondrial membrane potential and inhibiting cytochrome $\mathrm{c}$ release into the cytoplasm [74]. The S. chinensis lignan gomisin $\mathrm{N}$ increased the expression of mitochondria fatty acid oxidation and biogenesis genes in C2C12 myotubes [75]. Long-term schisandrin B treatment (1-30 mg/kg/d for 15 days) in cerebral ischemia/reperfusion (I/R) injury [27] and gentamicin-induced nephrotoxicity [26] models in rats revealed that schisandrin $B$ enhanced cerebral mitochondrial antioxidant status, preserved mitochondrial structural integrity, reduced $\mathrm{Ca}^{2+}$ load and cytochrome $\mathrm{c}$ 
release, and protected from mPTP opening [26,27]. Schisandrin B protected against carbon tetrachloride-induced hepatic damage by decreasing the sensitivity of mice liver mitochondria to the $\mathrm{Ca}^{2+}$-stimulated permeability transition, suppressing the $\mathrm{Ca}^{2+}$-loading, $\mathrm{ROS}$ production, and cytochrome c release [76]. Schisandrin B and $\gamma$-schisandrin $(2.5-5.0 \mu \mathrm{M})$ was protected from hypoxia/reoxygenation-induced apoptosis in H9c2 cardiomyocytes by decreasing the sensitivity to $\mathrm{Ca}^{2+}$-induced $\mathrm{mPTP}$ and increasing the mitochondrial membrane potential in both normal and damaged cells [25].

\section{Conclusions and Future Perspectives}

S. chinensis fruit extracts and their active compounds are potent antioxidants capable to scavenge ROS directly, activate the cellular antioxidant defense system components, and inhibit pro-oxidant enzymes, thus suppressing inflammation signal transduction pathways and protecting from apoptosis. S. chinensis bioactive compounds decrease the levels of liver function markers, block pro-oxidant enzyme activities, suppress inflammation, and exert anticancer effects, activating apoptosis and autophagy in cancer cells.

S. chinensis fruit preparations are well-tolerated and do not have serious adverse effects; therefore, they could be used as potential remedies to alleviate oxidative stress injuries and to restore normal cellular energy supply.

Author Contributions: Conceptualization, D.M.K. and J.B.; literature review and resources, D.M.K. and J.B.; writing — original draft preparation, D.M.K. and J.B.; writing—review and editing, D.M.K. and J.B.; visualization, D.M.K. and J.B.; supervision, J.B. Both authors have read and agreed to the published version of the manuscript.

Funding: This research received no external funding.

Data Availability Statement: Not applicable.

Acknowledgments: The authors wish to thank the Pharmaceutical and Health Technology Open Access Center for support of this study.

Conflicts of Interest: The authors declare no conflict of interest.

\section{References}

1. Hancke, J.L.; Burgos, R.A.; Ahumada, F. Schisandra chinensis (Turcz.) Baill. Fitoterapia 1999, 70, 451-471. [CrossRef]

2. Nowak, A.; Zakłos-Szyda, M.; Błasiak, J.; Nowak, A.; Zhang, Z.; Zhang, B. Potential of Schisandra chinensis (Turcz.) Baill. in human health and nutrition: A review of current knowledge and therapeutic perspectives. Nutrients 2019, 11, 333. [CrossRef]

3. Panossian, A.; Wikman, G. Pharmacology of Schisandra chinensis Bail.: An overview of Russian research and uses in medicine. J. Ethnopharmacol. 2008, 118, 183-212. [CrossRef] [PubMed]

4. Nasser, M.I.; Zhu, S.; Chen, C.; Zhao, M.; Huang, H.; Zhu, P. A comprehensive review on schisandrin B and its biological properties. Oxid. Med. Cell Longev. 2020, 2020, 2172740. [CrossRef] [PubMed]

5. Szopa, A.; Ekiert, R.; Ekiert, H. Current knowledge of Schisandra chinensis (Turcz.) Baill. (Chinese magnolia vine) as a medicinal plant species: A review on the bioactive components, pharmacological properties, analytical and biotechnological studies. Phytochem. Rev. 2017, 16, 195-218. [CrossRef] [PubMed]

6. Chen, X.; Zhang, Y.; Zu, Y.; Yang, L. Chemical composition and antioxidant activity of the essential oil of Schisandra chinensis fruits. Nat. Prod. Res. 2012, 26, 842-849. [CrossRef]

7. Szopa, A.; Ekiert, H. In vitro cultures of Schisandra chinensis (Turcz.) Baill. (Chinese magnolia vine)—A potential biotechnological rich source of therapeutically important phenolic acids. Appl. Biochem. Biotechnol. 2012, 166, 1941-1948. [CrossRef]

8. Mocan, A.; Crișan, G.; Vlase, L.; Crișan, O.; Vodnar, D.C.; Raita, O.; Gheldiu, A.M.; Toiu, A.; Oprean, R.; Tilea, I. Comparative studies on polyphenolic composition, antioxidant and antimicrobial activities of Schisandra chinensis leaves and fruits. Molecules 2014, 19, 15162-15179. [CrossRef]

9. Tong, H.; Zhao, B.; Du, F.; Tian, D.; Feng, K.; Sun, X. Isolation and physicochemical characterization of polysaccharide fractions isolated from Schisandra chinensis. Chem. Nat. Compd. 2012, 47, 969-970. [CrossRef]

10. Zhang, H.; Zhang, G.; Zhu, Z.; Zhao, L.; Fei, Y.; Jing, J.; Chai, Y. Determination of six lignans in Schisandra chinensis (Turcz.) Baill. Fruits and related Chinese multiherb remedies by HPLC. Food Chem. 2009, 115, 735-739. [CrossRef]

11. Gnabre, J.; Unlu, I.; Chang, T.C.; Lisseck, P.; Bourne, B.; Scolnik, R.; Jacobsen, N.E.; Bates, R.; Huang, R.C. Isolation of lignans from Schisandra chinensis with anti-proliferative activity in human colorectal carcinoma: Structure-activity relationships. J. Chromatogr. B Analyt. Technol. Biomed. Life Sci. 2010, 878, 2693-2700. [CrossRef] 
12. Slanina, J.; Páchniková, G.; Carnecká, M.; Porubová Koubíková, L.; Adámková, L.; Humpa, O.; Smejkal, K.; Slaninová, I. Identification of key structural characteristics of Schisandra chinensis lignans involved in P-glycoprotein inhibition. J. Nat. Prod. 2014, 77, 2255-2263. [CrossRef]

13. Lee, I.S.; Jung, K.Y.; Oh, S.R.; Park, S.H.; Ahn, K.S.; Lee, H.K. Structure-activity relationships of lignans from Schisandra chinensis as platelet activating factor antagonists. Biol. Pharm. Bull. 1999, 22, 265-267. [CrossRef]

14. Choi, Y.W.; Takamatsu, S.; Khan, S.I.; Srinivas, P.V.; Ferreira, D.; Zhao, J.; Khan, I.A. Schisandrene, a dibenzocyclooctadiene lignan from Schisandra chinensis: Structure-antioxidant activity relationships of dibenzocyclooctadiene lignans. J. Nat. Prod. 2006, 69, 356-359. [CrossRef]

15. Li, C.L.; Cheng, Y.Y.; Hsieh, C.H.; Tsai, T.H. Pharmacokinetics of schizandrin and Its pharmaceutical products assessed using a validated LC-MS/MS Method. Molecules 2018, 23, 173. [CrossRef] [PubMed]

16. Liang, D.; Wu, Z.; Liu, Y.; Li, C.; Li, X.; Yang, B.; Xie, H.; Sun, H. HPLC-MS/MS-mediated analysis of the pharmacokinetics, bioavailability, and tissue distribution of schisandrol B in rats. Int. J. Anal. Chem. 2021, 2021, 8862291. [CrossRef] [PubMed]

17. Chiang, T.Y.; Wang, H.J.; Wang, Y.C.; Chia-Hui Tan, E.; Lee, I.J.; Yun, C.H.; Ueng, Y.F. Effects of Shengmai San on key enzymes involved in hepatic and intestinal drug metabolism in rats. J. Ethnopharmacol. 2021, 271, 113914. [CrossRef]

18. Zhu, H.; Zhang, X.; Guan, J.; Cui, B.; Zhao, L.; Zhao, X. Pharmacokinetics and tissue distribution study of schisandrin B in rats by ultra-fast liquid chromatography with tandem mass spectrometry. J. Pharm. Biomed. Anal. 2013, 78-79, 136-140. [CrossRef]

19. Xu, H.; Gan, J.; Liu, X.; Wu, R.; Jin, Y.; Li, M.; Yuan, B. Gender-dependent pharmacokinetics of lignans in rats after single and multiple oral administration of Schisandra chinensis extract. J. Ethnopharmacol. 2013, 147, 224-231. [CrossRef] [PubMed]

20. Wang, Z.; You, L.; Cheng, Y.; Hu, K.; Wang, Z.; Cheng, Y.; Yang, J.; Yang, Y.; Wang, G. Investigation of pharmacokinetics, tissue distribution and excretion of schisandrin B in rats by HPLC-MS/MS. Biomed. Chromatogr. 2018, 32. [CrossRef]

21. Wan, C.K.; Tse, A.K.; Yu, Z.L.; Zhu, G.Y.; Wang, H.; Fong, D.W. Inhibition of cytochrome P450 3A4 activity by schisandrol A and gomisin A isolated from Fructus Schisandrae chinensis. Phytomedicine 2010, 17, 702-705. [CrossRef]

22. Blunder, M.; Pferschy-Wenzig, E.M.; Fabian, W.M.; Hüfner, A.; Kunert, O.; Saf, R.; Schühly, W.; Bauer, R. Derivatives of schisandrin with increased inhibitory potential on prostaglandin $\mathrm{E}(2)$ and leukotriene $\mathrm{B}(4)$ formation in vitro. Bioorg. Med. Chem. 2010, 18, 2809-2815. [CrossRef] [PubMed]

23. Hu, D.; Yang, Z.; Yao, X.; Wang, H.; Han, N.; Liu, Z.; Wang, Y.; Yang, J.; Yin, J. Dibenzocyclooctadiene lignans from Schisandra chinensis and their inhibitory activity on NO production in lipopolysaccharide-activated microglia cells. Phytochemistry 2014, 104, 72-78. [CrossRef] [PubMed]

24. Oh, S.Y.; Kim, Y.H.; Bae, D.S.; Um, B.H.; Pan, C.H.; Kim, C.Y.; Lee, H.J.; Lee, J.K. Anti-inflammatory effects of gomisin N, gomisin J, and schisandrin C isolated from the fruit of Schisandra chinensis. Biosci. Biotechnol. Biochem. 2010, 74, 285-291. [CrossRef]

25. Chiu, P.Y.; Luk, K.F.; Leung, H.Y.; Ng, K.M.; Ko, K.M. Schisandrin B stereoisomers protect against hypoxia/reoxygenation-induced apoptosis and inhibit associated changes in $\mathrm{Ca} 2+$-induced mitochondrial permeability transition and mitochondrial membrane potential in H9c2 cardiomyocytes. Life Sci. 2008, 82, 1092-1101. [CrossRef]

26. Chiu, P.Y.; Leung, H.Y.; Ko, K.M. Schisandrin B enhances renal mitochondrial antioxidant status, functional and structural integrity, and protects against gentamicin-induced nephrotoxicity in rats. Biol. Pharm. Bull. 2008, 31, 602-605. [CrossRef] [PubMed]

27. Chen, N.; Chiu, P.Y.; Ko, K.M. Schisandrin B enhances cerebral mitochondrial antioxidant status and structural integrity, and protects against cerebral ischemia/reperfusion injury in rats. Biol. Pharm. Bull. 2008, 31, 1387-1391. [CrossRef]

28. Fong, W.F.; Wan, C.K.; Zhu, G.Y.; Chattopadhyay, A.; Dey, S.; Zhao, Z.; Shen, X.L. Schisandrol A from Schisandra chinensis reverses P-glycoprotein-mediated multidrug resistance by affecting Pgp-substrate complexes. Planta Med. 2007, 73, 212-220. [CrossRef]

29. Hou, W.; Gao, W.; Wang, D.; Liu, Q.; Zheng, S.; Wang, Y. The protecting effect of deoxyschisandrin and schisandrin B on HaCaT cells against UVB-induced damage. PLoS ONE 2015, 10, e0127177. [CrossRef] [PubMed]

30. Li, L.; Lu, Q.; Shen, Y.; Hu, X. Schisandrin B enhances doxorubicin-induced apoptosis of cancer cells but not normal cells. Biochem. Pharmacol. 2006, 71, 584-595. [CrossRef]

31. Lee, K.; Ahn, J.H.; Lee, K.T.; Jang, D.S.; Choi, J.H. Deoxyschizandrin, isolated from Schisandra berries, induces cell cycle arrest in ovarian cancer cells and inhibits the protumoural activation of tumour-associated macrophages. Nutrients 2018, 10, 91. [CrossRef] [PubMed]

32. Lv, X.J.; Zhao, L.J.; Hao, Y.Q.; Su, Z.Z.; Li, J.Y.; Du, Y.W.; Zhang, J. Schisandrin B inhibits the proliferation of human lung adenocarcinoma A549 cells by inducing cycle arrest and apoptosis. Int. J. Clin. Exp. Med. 2015, 8, 6926-6936.

33. Zhang, Y.; Zhou, Z.W.; Jin, H.; Hu, C.; He, Z.X.; Yu, Z.L.; Ko, K.M.; Yang, T.; Zhang, X.; Pan, S.Y.; et al. Schisandrin B inhibits cell growth and induces cellular apoptosis and autophagy in mouse hepatocytes and macrophages: Implications for its hepatotoxicity. Drug Des. Dev. Ther. 2015, 9, 2001-2027.

34. Harris, E.D. Regulation of antioxidant enzymes1. FASEB J. 1992, 6, 2675-2683. [CrossRef]

35. Kim, S.Y.; Kim, T.B.; Moon, K.A.; Kim, T.J.; Shin, D.; Cho, Y.S.; Moon, H.B.; Lee, K.Y. Regulation of pro-inflammatory responses by lipoxygenases via intracellular reactive oxygen species in vitro and in vivo. Exp. Mol. Med. 2008, 40, 461-476. [CrossRef]

36. Kang, J.S.; Han, M.H.; Kim, G.Y.; Kim, C.M.; Kim, B.W.; Hwang, H.J.; Hyun, Y. Nrf2-mediated HO-1 induction contributes to antioxidant capacity of a Schisandrae Fructus ethanol extract in C2C12 myoblasts. Nutrients 2014, 6, 5667-5678. [CrossRef]

37. Li, X.J.; Zhao, B.L.; Liu, G.T.; Xin, W.J. Scavenging effects on active oxygen radicals by schizandrins with different structures and configurations. Free Radic. Biol. Med. 1990, 9, 99-104. 
38. Kim, S.R.; Lee, M.K.; Koo, K.A.; Kim, S.H.; Sung, S.H.; Lee, N.G.; Markelonis, G.J.; Oh, T.H.; Yang, J.H.; Kim, Y.C. Dibenzocyclooctadiene lignans from Schisandra chinensis protect primary cultures of rat cortical cells from glutamate-induced toxicity. J. Neurosci. Res. 2004, 76, 397-405. [CrossRef]

39. Ip, S.P.; Ma, C.Y.; Che, C.T.; Ko, K.M. Methylenedioxy group as determinant of schisandrin in enhancing hepatic mitochondrial glutathione in carbon tetrachloride-intoxicated mice. Biochem. Pharmacol. 1997, 54, 317-319. [CrossRef]

40. Szeto, Y.T.; Wong, S.C.; Wong, J.W.; Kalle, W.; Pak, S.C. In vitro antioxidation activity and genoprotective effect of selected Chinese medicinal herbs. Am. J. Chin. Med. 2011, 39, 827-838. [CrossRef] [PubMed]

41. Lam, P.Y.; Ko, K.M. Schisandrin B as a hormetic agent for preventing age-related neurodegenerative diseases. Oxid. Med. Cell Longev. 2012, 2012, 250825. [CrossRef]

42. Yan, T.; Shang, L.; Wang, M.; Zhang, C.; Zhao, X.; Bi, K.; Jia, Y. Lignans from Schisandra chinensis ameliorate cognition deficits and attenuate brain oxidative damage induced by D-galactose in rats. Metab. Brain. Dis. 2016, 31, 653-661. [CrossRef] [PubMed]

43. Giridharan, V.V.; Thandavarayan, R.A.; Sato, S.; Ko, K.M.; Konishi, T. Prevention of scopolamine-induced memory deficits by schisandrin B, an antioxidant lignan from Schisandra chinensis in mice. Free Radic. Res. 2011, 45, 950-958. [CrossRef]

44. Wu, Y.; Li, Z.C.; Yao, L.Q.; Li, M.; Tang, M. Schisandrin B alleviates acute oxidative stress via modulation of the Nrf2/Keap1mediated antioxidant pathway. Appl. Physiol. Nutr. Metab. 2019, 44, 1-6. [CrossRef]

45. Zeng, K.W.; Zhang, T.; Fu, H.; Liu, G.X.; Wang, X.M. Schisandrin B exerts anti-neuroinflammatory activity by inhibiting the Toll-like receptor 4-dependent MyD88/IKK/NF- $\mathrm{kB}$ signaling pathway in lipopolysaccharide-induced microglia. Eur. J. Pharmacol. 2012, 692, 29-37. [CrossRef] [PubMed]

46. Hu, D.; Li, C.; Han, N.; Miao, L.; Wang, D.; Liu, Z.; Wang, H.; Yin, J. Deoxyschizandrin isolated from the fruits of Schisandra chinensis ameliorates $\mathrm{A} \beta_{1-42}$-induced memory impairment in mice. Planta Med. 2012, 78, 1332-1336. [PubMed]

47. Mao, X.; Liao, Z.; Guo, L.; Xu, X.; Wu, B.; Xu, M.; Zhao, X.; Bi, K.; Jia, Y. Schisandrin C ameliorates learning and memory deficits by $\mathrm{A} \beta(1-42)$-induced oxidative stress and neurotoxicity in mice. Phytother. Res. 2015, 29, 1373-1380. [CrossRef]

48. Han, Y.; Yang, H.; Li, L.; Du, X.; Sun, C. Schisanhenol improves learning and memory in scopolamine-treated mice by reducing acetylcholinesterase activity and attenuating oxidative damage through SIRT1-PGC-1 $\alpha$-Tau signaling pathway. Int. J. Neurosci. 2019, 129, 110-118. [CrossRef]

49. Lu, H.; Liu, G.T. Anti-oxidant activity of dibenzocyclooctene lignans isolated from Schisandraceae. Planta Med. 1992, 58, 311-313. [CrossRef]

50. Leong, P.K.; Chiu, P.Y.; Chen, N.; Leung, H.; Ko, K.M. Schisandrin B elicits a glutathione antioxidant response and protects against apoptosis via the redox-sensitive ERK/Nrf2 pathway in AML12 hepatocytes. Free Radic. Res. 2011, 45, 483-495. [CrossRef]

51. Chiu, P.Y.; Mak, D.H.; Poon, M.K.; Ko, K.M. In vivo antioxidant action of a lignan-enriched extract of Schisandra fruit and an anthraquinone-containing extract of Polygonum root in comparison with schisandrin B and emodin. Planta Med. 2002, 68, 951-956. [CrossRef]

52. Ip, S.P.; Yiu, H.Y.; Ko, K.M. Differential effect of schisandrin B and dimethyl diphenyl bicarboxylate (DDB) on hepatic mitochondrial glutathione redox status in carbon tetrachloride intoxicated mice. Mol. Cell Biochem. 2000, 205, 111-114. [CrossRef] [PubMed]

53. Ip, S.P.; Poon, M.K.; Che, C.T.; Ng, K.H.; Kong, Y.C.; Ko, K.M. Schisandrin B protects against carbon tetrachloride toxicity by enhancing the mitochondrial glutathione redox status in mouse liver. Free Radic. Biol. Med. 1996, 21, 709-712. [CrossRef]

54. Ip, S.P.; Ko, K.M. The crucial antioxidant action of schisandrin B in protecting against carbon tetrachloride hepatotoxicity in mice: A comparative study with butylated hydroxytoluene. Biochem. Pharmacol. 1996, 52, 1687-1693. [CrossRef]

55. Ip, S.P.; Mak, D.H.; Li, P.C.; Poon, M.K.; Ko, K.M. Effect of a lignan-enriched extract of Schisandra chinensis on aflatoxin B1 and cadmium chloride-induced hepatotoxicity in rats. Pharmacol. Toxicol. 1996, 78, 413-416. [CrossRef] [PubMed]

56. Li, W.; Qu, X.N.; Han, Y.; Zheng, S.W.; Wang, J.; Wang, Y.P. Ameliorative effects of 5-hydroxymethyl-2-furfural (5-HMF) from Schisandra chinensis on alcoholic liver oxidative injury in mice. Int. J. Mol. Sci. 2015, 16, 2446-2457. [CrossRef] [PubMed]

57. Zhang, W.; Sun, Z.; Meng, F. Schisandrin B ameliorates myocardial ischemia/reperfusion injury through attenuation of endoplasmic reticulum stress-induced apoptosis. Inflammation 2017, 40, 1903-1911. [CrossRef]

58. Thandavarayan, R.A.; Giridharan, V.V.; Arumugam, S.; Suzuki, K.; Ko, K.M.; Krishnamurthy, P.; Watanabe, K.; Konishi, T. Schisandrin B prevents doxorubicin induced cardiac dysfunction by modulation of DNA damage, oxidative stress and inflammation through inhibition of MAPK/p53 signaling. PLoS ONE 2015, 10, e0119214. [CrossRef]

59. Chen, N.; Ko, M. Schisandrin B-induced glutathione antioxidant response and cardioprotection are mediated by reactive oxidant species production in rat hearts. Biol. Pharm. Bull. 2010, 33, 825-829. [CrossRef]

60. You, J.S.; Pan, T.L.; Hou, Y.C. Schisandra chinensis protects against adriamycin-induced cardiotoxicity in rats. Chang. Gung Med. J. 2006, 29, 63-70.

61. Li, P.C.; Mak, D.H.; Poon, M.K.; Ip, S.P.; Ko, K.M. Myocardial protective effect of Sheng Mai San (SMS) and a lignan-enriched extract of Fructus Schisandrae, in vivo and ex vivo. Phytomedicine 1996, 3, 217-221. [CrossRef]

62. Zhu, S.; Wang, Y.; Chen, M.; Jin, J.; Qiu, Y.; Huang, M.; Huang, Z. Protective effect of schisandrin B against cyclosporine A-induced nephrotoxicity in vitro and in vivo. Am. J. Chin. Med. 2012, 40, 551-566. [CrossRef]

63. Zhong, S.; Nie, Y.C.; Gan, Z.Y.; Liu, X.D.; Fang, Z.F.; Zhong, B.N.; Tian, J.; Huang, C.Q.; Lai, K.F.; Zhong, N.S. Effects of Schisandra chinensis extracts on cough and pulmonary inflammation in a cough hypersensitivity guinea pig model induced by cigarette smoke exposure. J. Ethnopharmacol. 2015, 165, 73-82. [CrossRef] [PubMed] 
64. Dilshara, M.G.; Jayasooriya, R.; Kang, C.H.; Lee, S.; Park, S.R.; Jeong, J.W.; Choi, Y.H.; Seo, Y.T.; Jang, Y.P.; Kim, G.Y. Downregulation of pro-inflammatory mediators by a water extract of Schisandra chinensis (Turcz.) Baill fruit in lipopolysaccharide-stimulated RAW 264.7 macrophage cells. Environ. Toxicol. Pharmacol. 2013, 36, 256-264. [CrossRef] [PubMed]

65. Guo, L.Y.; Hung, T.M.; Bae, K.H.; Shin, E.M.; Zhou, H.Y.; Hong, Y.N.; Kang, S.S.; Kim, H.P.; Kim, Y.S. Anti-inflammatory effects of schisandrin isolated from the fruit of Schisandra chinensis Baill. Eur. J. Pharmacol. 2008, 591, 293-299. [CrossRef]

66. Ci, X.; Ren, R.; Xu, K.; Li, H.; Yu, Q.; Song, Y.; Wang, D.; Li, R.; Deng, X. Schisantherin A exhibits anti-inflammatory properties by down-regulating NF-kappaB and MAPK signaling pathways in lipopolysaccharide-treated RAW 264.7 cells. Inflammation 2010, 33, 126-136. [CrossRef] [PubMed]

67. Liao, S.; Zhou, K.; Li, D.; Xie, X.; Jun, F.; Wang, J. Schisantherin A suppresses interleukin-1ß-induced inflammation in human chondrocytes via inhibition of NF-kB and MAPKs activation. Eur. J. Pharmacol. 2016, 780, 65-70. [CrossRef]

68. Abate, M.; Festa, A.; Falco, M.; Lombardi, A.; Luce, A.; Grimaldi, A.; Zappavigna, S.; Sperlongano, P.; Irace, C.; Caraglia, M.; et al. Mitochondria as playmakers of apoptosis, autophagy and senescence. Semin. Cell Dev. Biol. 2020, 98, 139-153. [CrossRef]

69. Dröse, S.; Brandt, U.; Wittig, I. Mitochondrial respiratory chain complexes as sources and targets of thiol-based redox-regulation. Biochim. Biophys. Acta 2014, 1844, 1344-1354. [CrossRef] [PubMed]

70. Piao, Z.; Song, L.; Yao, L.; Zhang, L.; Lu, Y. Schisandrin restores the amyloid $\beta$-induced impairments on mitochondrial function, energy metabolism, biogenesis, and dynamics in rat primary hippocampal neurons. Pharmacology 2021, 1-11. [CrossRef]

71. Li, R.; Yang, W. Gomisin J inhibits the glioma progression by inducing apoptosis and reducing HKII-regulated glycolysis. Biochem. Biophys. Res. Commun. 2020, 529, 15-22. [CrossRef]

72. Jang, Y.; Lee, J.H.; Lee, M.J.; Kim, S.J.; Ju, X.; Cui, J.; Zhu, J.; Lee, Y.L.; Namgung, E.; Sung, H.W.J.; et al. Schisandra extract and ascorbic acid synergistically enhance cognition in mice through modulation of mitochondrial respiration. Nutrients 2020, $12,897$. [CrossRef]

73. Ding, M.; Shu, P.; Gao, S.; Wang, F.; Gao, Y.; Chen, Y.; Deng, W.; He, G.; Hu, Z.; Li, T. Schisandrin B protects human keratinocytederived $\mathrm{HaCaT}$ cells from tert-butyl hydroperoxide-induced oxidative damage through activating the Nrf2 signaling pathway. Int. J. Mol. Med. 2018, 42, 3571-3581. [CrossRef] [PubMed]

74. Choi, Y.H. Schisandrin A prevents oxidative stress-induced DNA damage and apoptosis by attenuating ROS generation in C2C12 cells. Biomed. Pharmacother. 2018, 106, 902-909. [CrossRef] [PubMed]

75. Jung, D.Y.; Kim, J.H.; Lee, H.; Jung, M.H. Antidiabetic effect of gomisin N via activation of AMP-activated protein kinase. Biochem. Biophys. Res. Commun. 2017, 494, 587-593. [CrossRef] [PubMed]

76. Chiu, P.Y.; Leung, H.Y.; Siu, A.H.; Poon, M.K.; Ko, K.M. Schisandrin B decreases the sensitivity of mitochondria to calcium ion-induced permeability transition and protects against carbon tetrachloride toxicity in mouse livers. Biol. Pharm. Bull. 2007, 30, 1108-1112. [CrossRef] 